\title{
UTILIZATION OF HEALTHCARE SERVICES \& HEALTHCARE EXPENDITURE PATTERNS IN THE RURAL HOUSEHOLDS OF NEPAL
} \author{
Shin 5 \\ 1. Department of Public Health, La Grandee International College, Nepal \\ 2. Graduate School of Public Health, Busan Medical Campus, Inje University, South Korea \\ 3. School of Health and Allied Sciences, Pokhara University, Nepal \\ 4. Department of Occupational Health \& Safety, Inje University, South Korea
}

Sachin Pokharel', Shiva Raj Acharya2*, Sandip Pahari3, Deog Hwan Moon², Yong Chul

Correspondence: sameeracharya39@gmail.com

\section{ABSTRACT}

\section{BACKGROUND}

Healthcare financing as a lever to move closer to universal health coverage. Financing health care has been identified as a barrier to access to health care and increases the likelihood of impoverishment of households. There is still limited study and information on healthcare service utilization in the rural community of Nepal. Our study aims to assess utilization of healthcare services \& patterns of healthcare expenditure in the rural households of Nepal.

\section{METHODS}

A community-based research study was conducted among 341 rural households of Tanahun District, Nepal. A Chi-square test was used for assessing the associated factors with healthcare utilization.

\section{RESULTS}

The utilization of in-patient and out-patient health services was $89.9 \%$ and $10.1 \%$ respectively. The majority of households (88\%) had in USD less than $\$ 410$ annual household healthcare expenditure. The mean annual healthcare expenditure was found to be $\$ 279$. Nearly three-fourths $(71.4 \%)$ of households had annual expenditure on medicine more than $\$ 40$ with mostly on allopathic medicine (93.4\%). The majority of participants (70\%) mentioned that the healthcare expenditure was a burden to their household.

\section{CONCLUSION}

Despite the higher knowledge of health insurance, the involvement was found to be very low \& poor. Educational status, knowledge about insurance, privileged ethnicity, religion, income source were the major factors associated with the utilization of healthcare services. Awareness \& promotion programs focusing on rural communities should be implemented with affordable health services.

\section{KEYWORDS}

healthcare utilization, healthcare services, health insurance, healthcare expenditure, rural household 
health care expenditure among people of the rural municipality in Tanahun, Province No. 4 of Nepal.

Health financing levers to move closer to universal health coverage lie in three interrelated areas: raising funds for health, reducing financial barriers to access through prepayment and subsequent pooling of funds in preference to direct out-of-pocket payments and allocating or using funds in a way that promotes efficiency and equity. [1] In low-income countries, direct out-ofpocket (OOP) payments are the principal means of health system financing. [2] Public health expenditure to GDP ratio has remained low in developing countries and the general public has no choice but to seek healthcare from their own pocket, which has remained the dominant source of financing. [3] Significant Out of pocket expenditure may lead households to a "financial catastrophe" in the absence of risk and payment pooling mechanisms or insurance. [4]

Globally, approximately 44 million households or more than 150 million individuals face cata- strophic health expenditure (CHE), and about 25 million households or more than 100 million individuals are pushed into poverty by the need to pay for services every year. In the South Asian region, this proportion has been estimated to reach up to $60 \%-70 \%$ of total expenditure due to poor public spending on health. In most of the low/middle-income countries, a large proportion of the money spent on healthcare comes from the out-of-pocket (OOP) expenditure of patients or their families. [22-28]

In Nepal, there has been estimated that 48-69\% households can experience financial hardship and often impoverishment as a result of their spending on health care. In the long term, financial protection against the risk of catastrophic health expenditure at household level can be achieved through tax-based health financing systems or social health insurance schemes or a combination of both. [25] Nepal has committed to the global community to achieve universal health coverage by 2030. As the government moves to progressively realize Universal Health Coverage (UHC), it remains committed to expand health services, increase the population coverage and reduce financial burdens for the citizens. [5,6,16-20, 27-31] Almost $50 \%$ of the Nepali health budget is made up of international aid. [7] More than half of Nepali women visited traditional healers for healthcare as the first choice of treatment. [8,9] The study was carried out to determine the patterns of

\section{MATERIALS AND METHODS}

\section{Study design \& population}

A quantitative, descriptive cross-sectional research study was carried out among 341 households of selected wards from the rural municipality in Tanahun, Province No. 4 of Nepal. Households that migrated into our study location since the time of less than one year were excluded from the study. The responsible person of the household who takes health care and other financial decisions were included for this study.

\section{Sampling technique \& sample size}

Initially, three wards were selected randomly by using simple random method and 125, 126, 90 households from each ward were selected using proportionate sampling respectively. Then, the households from each ward were selected through systematic random sampling. Sample size was calculated using the formula,

$$
n=\frac{Z^{2} p q N}{d^{2}(N-1)+Z^{2} p q}
$$

$\mathrm{Z}=$ standard normal variable at $95 \% \mathrm{Cl}(1.96), \mathrm{N}=$ Total number of households (4132) [21], $\mathrm{p}=$ estimated proportion of out of pocket expenditure $(p=0.68)$ based on the similar study [13], $q=1-p, d=$ desirable error (5\%). With the application of $10 \%$ non-response rate, the sample size of this study was 341 .

\section{Data collection \& management}

To refine the developed data collection tools, precise and accurate information, the tools was tested. $10 \%(n=35)$ of defined sample size were used to conduct pretesting of designed tools. The reliability of tools was tested in SPSS using Cronbach's Alpha which calculated value was found to be greater than 0.8 in average. It was conducted in Bandipur municipality of Nepal because of neighboring rural municipality with similar characteristics. Data collection was from June to August 2019 through face to face interview technique with structured questionnaire. Data were entered and coded in EpiData 3.1 and further analyzed in IBM SPSS version 21. Descriptive analysis used frequency, mean, median and standard deviation. Bivariate analysis using Chi-square $\left(x_{2}\right)$ test to determine the association between independent and dependent variables was utilised. 
Age, religion, ethnicity, location, family type, education, income source, occupation was assessed as socioeconomic variables. Healthcare utilization \& healthcare expenditure was considered as dependent variables for the study purpose. Approval for the study was taken from the ethical review board of Nepal Health Research Council (ERB No: 574/2019). Informed consent was taken from the respondents. The privacy of the information was maintained and used for the research purpose only.

\section{RESULTS}

As depicted in Table 1, most of the household members were Hindu. The majority of households were Janajati of the same race, language and customs (70.1\%). Agriculture was the main source of income by covering $44 \%$ of all income sources.

TABLE 1: SOCIO-DEMOGRAPHIC INFORMATION AND PATTERNS ON UTILIZATION OF HEALTH CARE SERVICES

\begin{tabular}{|c|c|c|}
\hline \multicolumn{3}{|c|}{ Socio-demographic information } \\
\hline Variables & Frequency(n) & Percentage (\%) \\
\hline \multicolumn{3}{|l|}{ Religion } \\
\hline Hindu & 287 & 84.2 \\
\hline Buddhist & 54 & 15.8 \\
\hline \multicolumn{3}{|l|}{ Caste } \\
\hline Brahmin & 27 & 7.9 \\
\hline Chhetri & 27 & 7.9 \\
\hline Janajati & 239 & 70.1 \\
\hline Dalit & 48 & 14.1 \\
\hline \multicolumn{3}{|l|}{ Income Source } \\
\hline Agriculture & 150 & 44.0 \\
\hline Government employee & 22 & 6.5 \\
\hline Service & 26 & 7.6 \\
\hline Remittance & 70 & 20.5 \\
\hline Business & 73 & 21.4 \\
\hline \multicolumn{3}{|c|}{ Utilization of health care services \& health insurance } \\
\hline \multicolumn{3}{|l|}{ Visit to health care facility } \\
\hline Yes & 296 & 86.8 \\
\hline No & 45 & 13.2 \\
\hline \multicolumn{3}{|l|}{ Types of services used } \\
\hline Outpatient care & 266 & 89.9 \\
\hline Inpatient care & 30 & 10.1 \\
\hline \multicolumn{3}{|l|}{ Regularity of Medicine } \\
\hline Yes & 91 & 26.7 \\
\hline No & 250 & 73.3 \\
\hline \multicolumn{3}{|l|}{ Types of medicine used } \\
\hline Allopathy & 85 & 93.4 \\
\hline Ayurveda & 6 & 6.6 \\
\hline
\end{tabular}




\begin{tabular}{|l|c|c|}
\hline \multicolumn{3}{|c|}{ Annual mean expenditure on medicine: NRs 5,700 (41\$) } \\
\hline Travelled abroad for medical treatment \\
\hline Yes & 332 & 2.6 \\
\hline No & 9 & 97.4 \\
\hline Heard about health insurance & 261 & 76.5 \\
\hline Yes & 80 & 23.5 \\
\hline No & 94 & 36.0 \\
\hline Have health insurance (n=262) & 167 & 64.0 \\
\hline Yes & & \\
\hline No & & \\
\hline \multicolumn{2}{|c|}{ Mean expenditure on abroad treatment: NRs 1,72,000 (\$1412\$) } \\
\hline
\end{tabular}

IUSD $=119$ Nepali rupees

The majority of household members were admitted or seen by doctors and among them, most of the household members (89.9\%) used OPD Services and only $10.1 \%$ were admitted in health services. Most of the households (73.3\%) didn't take any kind of medicine regularly. Among those who take medicine regularly, the mean expenditure was NRs 5,700 (\$41). The majority of households (93.4\%) used the allopathy type of medicine. Most of the households had visited health post (27.9\%) followed by private hospital
(23.2\%), pharmacy (22.4\%), government hospital (19.4\%), Ayurveda centres (3.5\%), primary health care centers (3\%) and community hospitals $(0.7 \%)$. The study shows that the majority of household members hadn't traveled abroad for medical treatment \& the mean expenditure on abroad treatment was about NRs 1,72,000 (\$1412\$). Most of the households had heard about health insurance but only around one-third of households had health insurance.

TABLE 2: HOUSEHOLD EXPENDITURE PATTERNS ON VARIOUS MEDICAL SERVICES

\begin{tabular}{|c|c|c|c|c|}
\hline \multirow{2}{*}{ SERVICES } & \multirow{2}{*}{ DEPARTMENTS } & \multicolumn{3}{|c|}{ EXPENDITURE (IN NRS) } \\
\hline & & TOTAL & MEAN & S. D. \\
\hline \multirow{4}{*}{ Bed } & OPD & 23,500 & 1566.67 & 979.553 \\
\hline & IPD & $1,36,500$ & 5687.50 & 5042.88 \\
\hline & ICU & 30,000 & 30,000 & - \\
\hline & Emergency & 58,000 & 2900 & 2516.26 \\
\hline \multirow[t]{4}{*}{ Medicine } & OPD & $9,95,000$ & 7653.85 & $13,164.63$ \\
\hline & IPD & $4,16,500$ & 16.660 & $11,128.71$ \\
\hline & ICU & 30,000 & 30,000 & - \\
\hline & Emergency & 19,500 & 1500 & 1274.75 \\
\hline \multirow[t]{3}{*}{ X-Ray } & OPD & 22,500 & 2812.50 & 2137.042 \\
\hline & IPD & 71,500 & 3250 & 20333.93 \\
\hline & ICU & 80,000 & 80,000 & - \\
\hline Eye Care & OPD & 30,000 & 15,000 & 7071.068 \\
\hline Dental Care & OPD & 35,000 & 8750 & 7071.068 \\
\hline \multicolumn{5}{|c|}{ Mean annual healthcare expenditure: NRs 34,000 (279\$) } \\
\hline
\end{tabular}

IUSD $=119$ Nepali rupees 
The visit to health care services is significantly associated with socio-demographic variables such as family type ( $x 2$ $=7.446, p \leq 0.05)$, educational level ( $x 2=26.035, p \leq 0.01$ ), the main source of income ( $x 2=14.241, p \leq 0.01)$. It is found that involvement in health insurance was significantly associated with socio-demographic variables such as ethnicity ( $x 2=13.068, p \leq 0.01$ ), educational level ( $x 2=33.192$, $\mathrm{p} \leq 0.01)$. Our study showed that type of utilized healthcare service was significantly associated with religion $(x 2=6.071$, $p \leq 0.05)$, income source ( $x 2=18.753, p \leq 0.01)$ but ethnicity of participants wasn't found to be associated with healthcare service utilization.

TABLE 3: FACTORS ASSOCIATED WITH UTILIZATION OF HEALTHCARE SERVICES

\begin{tabular}{|c|c|c|c|c|c|}
\hline \multicolumn{3}{|c|}{ Admitted or seen by doctors } & \multirow{2}{*}{$\begin{array}{l}x^{2} / \text { Fisher } \\
\text { Exact }\end{array}$} & \multirow[t]{2}{*}{$d f$} & \multirow[t]{2}{*}{$p$-value } \\
\hline Variables & No & Yes & & & \\
\hline \multicolumn{6}{|l|}{ Family type } \\
\hline Nuclear & $17(11.6 \%)$ & $130(88.4 \%)$ & \multirow{3}{*}{7.446} & \multirow{3}{*}{2} & \multirow{3}{*}{$0.024^{*}$} \\
\hline Joint & $19(9 \%)$ & $144(88.3 \%)$ & & & \\
\hline Extended & $9(29 \%)$ & $22(71 \%)$ & & & \\
\hline \multicolumn{6}{|l|}{ Educational level } \\
\hline Illiterate & $17(37 \%)$ & $29(63 \%)$ & \multirow{6}{*}{26.035} & \multirow{6}{*}{5} & \multirow{6}{*}{$0.001^{* *}$} \\
\hline Informal & $12(17.9 \%)$ & $55(82.1 \%)$ & & & \\
\hline Basic & $10(7,8 \%)$ & $119(92.2 \%)$ & & & \\
\hline Secondary & $5(6.3 \%)$ & $74(93.7 \%)$ & & & \\
\hline Bachelor & $1(5.6 \%)$ & $17(94.4 \%)$ & & & \\
\hline Masters or above & $0(0.0 \%)$ & $2(100 \%)$ & & & \\
\hline \multicolumn{6}{|l|}{ Income Source } \\
\hline Agriculture & $30(20 \%)$ & $120(80 \%)$ & \multirow{5}{*}{14.241} & \multirow{5}{*}{4} & \multirow{5}{*}{$0.001^{* *}$} \\
\hline $\begin{array}{l}\text { Government } \\
\text { employee }\end{array}$ & $0(0.0 \%)$ & $22(100 \%)$ & & & \\
\hline Service & $0(0.0 \%)$ & $26(100 \%)$ & & & \\
\hline Remittance & $7(10 \%)$ & $63(90 \%)$ & & & \\
\hline Business & $8(11 \%)$ & $65(89 \%)$ & & & \\
\hline \multicolumn{3}{|c|}{ Involvement in health insurance } & & & \\
\hline Variables & No & Yes & & & \\
\hline Ethnicity & & & & & \\
\hline Brahmin & $9(37.5 \%)$ & $15(62.5 \%)$ & \multirow{4}{*}{13.068} & \multirow{4}{*}{3} & \multirow{4}{*}{$0.004^{* *}$} \\
\hline Chettri & $17(70.8 \%)$ & $7(29.2 \%)$ & & & \\
\hline Janajati & $121(63.7 \%)$ & $69(36.3 \%)$ & & & \\
\hline Dalit & $20(87 \%)$ & $3(13 \%)$ & & & \\
\hline
\end{tabular}




\begin{tabular}{|c|c|c|c|c|c|}
\hline Educational level & & & & & \\
\hline Illiterate & $15(71.4 \%)$ & $6(28.6 \%)$ & \multirow{6}{*}{33.192} & \multirow{6}{*}{5} & \multirow{6}{*}{$0.001^{* *}$} \\
\hline Informal & $28(71.8 \%)$ & $11(28.2 \%)$ & & & \\
\hline Basic & $79(75.2 \%)$ & $26(24.8 \%)$ & & & \\
\hline Secondary & $43(55.8 \%)$ & $34(44.2 \%)$ & & & \\
\hline Bachelor & $2(11.8 \%)$ & $15(88.2 \%)$ & & & \\
\hline Masters or above & $0(0.0 \%)$ & $2(100 \%)$ & & & \\
\hline \multicolumn{3}{|c|}{ Types of health services } & & & \\
\hline Variables & $\begin{array}{c}\text { Outpatient } \\
\text { care }\end{array}$ & Inpatient care & & & \\
\hline \multicolumn{6}{|l|}{ Religion } \\
\hline Hindu & $225(91.8 \%)$ & $20(8.2 \%)$ & \multirow[t]{2}{*}{6.071} & \multirow[t]{2}{*}{1} & \multirow[t]{2}{*}{$0.014^{*}$} \\
\hline Buddhist & $41(80.4 \%)$ & $10(19.6 \%)$ & & & \\
\hline \multicolumn{6}{|l|}{ Ethnicity } \\
\hline Brahmin & $23(92 \%)$ & $2(8.0 \%)$ & \multirow{4}{*}{7.173} & \multirow{4}{*}{3} & \multirow{4}{*}{0.051} \\
\hline Chhetri & $22(84.6 \%)$ & $4(15.4 \%)$ & & & \\
\hline Janajati & $181(88.3 \%)$ & $24(11.7 \%)$ & & & \\
\hline Dalit & $40(100 \%)$ & $0(0.0 \%)$ & & & \\
\hline \multicolumn{6}{|l|}{ Income Source } \\
\hline Agriculture & $117(97.5 \%)$ & $3(2.5 \%)$ & \multirow{5}{*}{18.752} & \multirow{5}{*}{4} & \multirow{5}{*}{$0.001^{* *}$} \\
\hline $\begin{array}{l}\text { Government } \\
\text { employee }\end{array}$ & $21(95.5 \%)$ & $1(2.2 \%)$ & & & \\
\hline Service & $23(88.5 \%)$ & $3(11.5 \%)$ & & & \\
\hline Remittance & $50(79.4 \%)$ & $13(20.6 \%)$ & & & \\
\hline Business & $55(84.6 \%)$ & $10(15.4 \%)$ & & & \\
\hline
\end{tabular}

\section{DISCUSSION}

According to this study, the annual expenditure on medical health care was less than fifty thousand rupees which are similar to the findings of the study among industrial workers of Nepal in which annual expenditure was about thirty thousand rupees. [10] The main reason may be because Nepal is a developing country and most people cannot invest enough budget for health care. But in the study conducted in low-income societies of Iran, the annual expenditure of healthcare was about eight thousand rupees as compared to the present study. [11] This may have occurred because of the existence of health insurance and free health care services in that study area and the context of the current study, where utilization of free health care services is not good. 
In this study, the availability of medicine was found to be nearly three-fourth (71.2\%) whereas in one of the studies from Nepal, a free health care scheme was found to be 92.4\% which differs from present study findings. [12] It could be due to a lack of access and knowledge on free health services. In the present study, less than one-fourth (18.8\%) of household members were admitted to health institutions. About $16 \%$ of household members were admitted to health institutions [10] which is similar to our findings. It may be due to the working power and healthy life of the respondents. The expenditure was mainly on beds, medicine, x-ray, eye care, and dental care. Regarding beds, the highest expenditure was on IPD (Mean= NRs 5687.50, S.D.= NRs 5042.88, Sum $=$ NRs 1,36,500).

Only about fifteen percent (14.5\%) of households didn't utilize health services to treat the above-mentioned diseases whereas, in the study done on Nepali older adults, more than one-fourth (30\%) of participants didn't utilize health services to treat such diseases which are more than our findings. [13] In another study among industrial workers in Nepal, the utilization of out-patient and in-patient health services was $89.9 \%$ and $10 \%$ respectively which is similar to the present study that 87.5 and $14.6 \%$ respectively. [10] This may have occurred because the outpatient services are used commonly. According to the present study, the percentage of household traveling abroad for medical treatment remains very low (2.6\%) and among them, most of the household spent about one lakh fifty thousand rupees to two lakh rupees $(\$ 1228 \$ \sim 1638)$ for the treatment which is low in comparison to the study conducted on low- and middle-income people of the Maldives. [14] It may have occurred because of the low annual household income of our study households.

In our study, more than half (76.5\%) of households knew health insurance and among then only $36 \%$ of households were involved in such a scheme. In the social health insurance in implemented districts of Nepal, only very few (5\%) of households had health insurance. [15] The huge difference occurred because there were many rural areas where many illiterate people lived and the people of those areas lacked information about health insurance. Among health insurance clients, nearly three-fourth (69.1\%) of clients benefited from the services. Among involved households, about three-fourth of them were satisfied with health insurance services. The limitation of our study is focusing on the province 4 of Nepal. Studies focusing on the health utilization patterns in other provinces and in the nation may have more indepth picture of the health service utilization in Nepal. However, this result supported the growing effectiveness of health insurance programs in the rural municipalities of Province No. 4 of Nepal.

\section{CONCLUSION}

The utilization of health care services was found to be inadequate. Rural community household involvement in health insurance service is still low \& poor. In Nepal, limited study \& facts are available on healthcare service utilization in rural households. Ethnicity, family type, educational level, and annual income were the major determinants for the utilization of health care services. The ayurvedic type of medicine should be promoted and the government should invest more in health care finance focusing on rural areas.

\section{FUNDING AND CONFLICT OF INTEREST}

This research study work was conducted without any funding. We declare that we don't have any conflicting interest.

\section{ACKNOWLEDGEMENT}

We are thankful to all the households who gave their valuable time and information during this research study.

\section{References}

1. Lee NC, Chang YH, Tu HT, Kuo CF, Yu KH, See LC. Comparison of the implementation of extra root canal treatment before and after fee schedule change in the Taiwan National Health Insurance System. Journal of dental sciences. 2018;13(2):145-50.

2. Joe W. Distressed financing of household out-ofpocket health care payments in India: incidence and correlates. Health policy and planning. 2015;30(6):72841.

3. Khalid M, Sattar A. Households Study on Out-of-Pocket Health Expenditures in Pakistan. Forman Journal of Economic Studies. 2016;12:75-88.

4. Beogo I, Huang N, Gagnon M-P, Amendah DD. Outof-pocket expenditure and its determinants in the context of private healthcare sector expansion in subSaharan Africa urban cities: evidence from household survey in Ouagadougou, Burkina Faso. BMC research notes. $2016 ; 9(1): 34$. 
5. Ghimire M, Ayer R, Kondo M. Cumulative incidence, distribution, and determinants of catastrophic health expenditure in Nepal: results from the living standards survey. International journal for equity in health. 2018;17(1):23.

6. Nepal health sector strategy 2015-2020. Kathmandu, Nepal: Ministy of Health and Population, 2015.

7. Health Budgeting and Financing in Nepal: Policy Perspectives Kathmandu: Ministry of Health and Population. 2018.

8. Adhikari D, Rijal DP. Factors affecting health seeking behavior of senior citizens of Dharan. Journal of Nobel Medical College. 2014;3(1):50-7.

9. Shrestha MV, Paudel L, Pant S, Neupane S, Manandhar N. Health seeking behavior among women in Bhimtar, Sindhupalchowk district of Nepal. International Journal Of Community Medicine And Public Health. 2017;4(6):1854-7.

10. Pyakurel P, Tripathy JP, Oo MM, Acharya B, Pyakurel U, Singh SB, et al. Catastrophic health expenditure among industrial workers in a large-scale industry in Nepal, 2017: a cross-sectional study. BMJ open. 2018:8(11):e022002.

11. Kavosi Z, Rashidian A, Pourreza A, Majdzadeh R, Pourmalek $F$, Hosseinpour AR, et al. Inequality in household catastrophic health care expenditure in a low-income society of Iran. Health policy and planning. 2012;27(7):613-23.

12. Adhikari SR, Sapkota DS, Thapa A, Pandey AR. Evaluation of Nepal's Free Health Care Scheme from Health System Perspective: A Qualitative Analysis. Journal of Nepal Health Research Council. 2018;16(41):372-7.

13. Acharya S, Ghimire S, Jeffers EM, Shrestha N. Health Care Utilization and Health Care Expenditure of Nepali Older Adults. Frontiers in public health. 2019;7.

14. Suzana M, Walls $H$, Smith $R$, Hanefeld J. Evaluation of public subsidy for medical travel: does it protect against household impoverishment? International journal for equity in health. 2018;17(1):30.

15. Pokharel R, Silwal PR. Social health insurance in Nepal: A health system departure toward the universal health coverage. The International journal of health planning and management. 2018.
16. Acharya SR, Pandey A. Place of delivery and newborn care practices in Kaski district: a cross sectional study from Nepal. Journal of Biomedical Sciences. 2014;1 (2):6-11.

17. Raj Acharya S and Kumar Ray A. Prevalence and Root Cause of Uterine Prolapse in Married Woman with Reproductive-Aged (MWRA) at VDC Level in Nepal. Austin J Public Health Epidemiol. 2017; 4(3): 1064.

18. Acharya SR, Poudel S. Factors associated with maternal and neonatal health care practices: a study from Nepal. Int J Health Sci Res. 2020; 10(2):186-192.

19. Acharya SR. Utilization Pattern of Personal Protective Equipment's among Industrial Workers of Nawalparasi, Nepal. Health Prospect-Journal of Public Health. 2014; 13(2): 24-27.

20. Bhattarai, S., Subedi, S. and Acharya, S.R. Factors Associated With Early Menarche among Adolescents Girls : A Study from Nepal. SM Journal of Coummunity Medicine. 2018; 4 (1): 1028.

21. Central Bureau of Statistics National Population and Housing Census 2011. National Report. Government of Nepal, National Planning Commission Secretariat. Kathmandu. 2012.

22. World Health Organization. World health statistics 2015: World Health Organization. 2015.

23. Rao MG, Choudhury M. Health care financing reforms in India. National Institute of Public Finance and Policy New Delhi. 2012.

24. Saito E, Gilmour S, Rahman MM, Gautam GS, Shrestha PK, Shibuya K. Catastrophic household expenditure on health in Nepal: a cross-sectional survey. Bulletin of the World Health Organization. 2014; 92:760-7.

25. Garg CC, Karan AK. Reducing out-of-pocket expenditures to reduce poverty: a disaggregated analysis at rural-urban and state level in India. Health policy and planning. 2008;24(2):1 16-28.

26. Acharya SR, Moon DH, Shin YC. Assessment of VOCs, PM10, and Formaldehyde Exposure in the Hair Salons of South Korea. J Environ Health Sustain Dev. 2020; 5(4): $1103-8$.

27. Acharya SR, Bhatta J, Timilsina DP. Factors associated with nutritional status of women of reproductive age group in rural, Nepal. Asian Pacific Journal of Health Sciences. 2017; 4(4): 19-24. 
28. Acharya SR, Adhikari S, Pahari S et al. Malnutrition and Associated Factors with Nutritional Status among Orphan Children: An Evidence-Based Study from Nepal. International Journal of Child Health and Nutrition. 2020; 9(3):125-132.

29. Banstola S, Acharya SR, Shin YC. Health problems among child labour in the brick industries of Nepal. Austin J Public Health Epidemiol 2019; 6(1):1083.

30. Acharya SR, Shin YC, Moon DH. COVID-19 outbreak and suicides in Nepal: Urgency of immediate action. International Journal of Social Psychiatry. 2020.

31. Baral S, Moon DH, Shin YC et al. Perception of Food Hygiene and Nutritive Value of the Food. The Korean Journal of Food \& Health Convergence. 2020; 6(4): 1 6. 